\title{
Cancer cachexia: Physical activity and muscle force in tumour-bearing rats
}

\author{
MIRIAM TOLEDO ${ }^{1}$, SILVIA BUSQUETS ${ }^{1}$, SONIA SIRISI ${ }^{1}$, ROBERTO SERPE $^{2}$, MARCEL ORPI $^{1}$, \\ JOANA COUTINHO $^{1}$, RAQUEL MARTINEZ ${ }^{1}$, FRANCISCO J. LOPEZ-SORIANO ${ }^{1}$ and JOSEP M. ARGILÉS ${ }^{1}$ \\ ${ }^{1}$ Cancer Research Group, Departament de Bioquímica i Biologia Molecular, Facultat de Biologia, Universitat de Barcelona, \\ Institut de Biomedicina de la Universitat de Barcelona, Barcelona, Spain; ${ }^{2}$ Department of Medical Oncology, \\ Azienda Ospedaliero Universitaria di Cagliari, S.S, Monserrato (CA), Italy
}

Received April 30, 2010; Accepted July 6, 2010

DOI: $10.3892 /$ or_00001060

\begin{abstract}
Rats bearing the Yoshida AH-130 ascites hepatoma are subjected to substantial weight loss, which is accompanied by anorexia at the end of the tumour cycle. Total physical activity (measured using the IR Actimeter system and Actitrack software) was determined during 11 days in control and tumour-bearing animals, skeletal muscle strength being also by the grip-strength test. The results presented clearly show that the presence of the tumour induces an earlier decrease in physical performance, which affects both skeletal muscle force and physical activity (both locomotor movements and stereotyped movements and distance travelled, among others parameters).
\end{abstract}

\section{Introduction}

The Yoshida AH-130 ascites hepatoma is a highly cachectic rat tumour of rapid growth and poorly differentiated cells. This tumour is characterized by a relatively short doubling time of one day $(1,2)$ and is widely used in experimental studies $(3,4)$. The implantation of the tumour leads to a very fast weight loss, which is accompanied by anorexia in the terminal state. The weight loss is associated with both fat and skeletal muscle wasting, as has been shown previously by our research group (5-7).

These abnormalities together associated with weight loss, muscle loss and atrophy, anaemia and alterations in carbohydrate, lipid and protein metabolism (8-10) are the main characteristics of the cancer cachexia syndrome. The degree of cachexia is inversely correlated with the survival time of the patient and it always implies a poor prognosis

Correspondence to: Dr Josep M. Argilés, Cancer Research Group, Departament de Bioquímica i Biologia Molecular, Facultat de Biologia, Universitat de Barcelona, Diagonal 645, 08028Barcelona, Spain

E-mail: jargiles@ub.edu

Key words: physical activity, grip force, cancer cachexia, skeletal muscle
(11-13). Perhaps one of the most relevant characteristics of cachexia is that of asthenia, which reflects the substantial muscle waste that takes place in the cachectic cancer patient (14). Lean body mass depletion is one of the main trends of cachexia and it involves not only skeletal muscle but it also affects cardiac proteins, resulting in considerable alterations in heart performance. In addition to the increased muscle protein degradation found during cancer growth, the presence of the tumour also induces an increased rate of DNA fragmentation in skeletal muscle in both rats and mice (15). All these mechanisms contribute to a marked muscle wasting.

The aim of the present investigation was to determine the influence of the cachectic state on the physical performance of the animals.

\section{Materials and methods}

Animals. Male Wistar rats (Interfauna, Barcelona, Spain), five weeks of age were used in the different experiments. The animals were maintained at $22 \pm 2{ }^{\circ} \mathrm{C}$ with a regular lightdark cycle (light on from 08:00 a.m. to 08:00 p.m.) and had free access to food and water. The body weight and food intake was measured daily. All animal manipulations were made in accordance with the European Community guidelines for the use of laboratory animals.

Tumour inoculation. Rats were divided into two groups, namely controls and tumour hosts. The latter received an intraperitoneal inoculum of $10^{8} \mathrm{AH}-130$ Yoshida ascites hepatoma cells obtained from exponential tumours (16). On different days after tumour transplantation, the animals were weighed and anaesthetized with an i.p. injection of ketamine/ xylazine mixture $(3: 1)$ (Imalgene $^{\circledR}$ and Rompun ${ }^{\circledR}$, respectively). The tumour was harvested from the peritoneal cavity and its volume and cellularity evaluated. Tissues were rapidly excised, weighed, and frozen in liquid nitrogen.

Total physical activity. Total physical activity (IR Actimeter system and Actitrack software from Panlab, Barcelona) was determined during 11 days in control and tumour-bearing animals using activity sensors that translate individual changes in the infrared pattern caused by movements of the animals 
into arbitrary activity counts. Data were collected for a total period of $24 \mathrm{~h}$ separated into 12 -h periods (dark and light phases). For the measurents, animals remained in their home cage, a frame containing an infra-red beam system was placed on the outside of the cage. This minimised stress to the animals.

Grip force assessment. Skeletal muscular strength in rats was quantified by the grip-strength test $(17,18)$. The gripstrength device (Panlab-Harvard Apparatus, Spain) comprised a triangular pull bar connected to an isometric force transducer (dynamometer). Basically, the grip strength meter was positioned horizontally and the rats are held by the tail and lowered towards the device. The animals are allowed to grasp the triangular pull bar and were then pulled backwards in the horizontal plane. The force applied to the bar just before it lost grip was recorded as the peak tension. At least three measurements were taken per rat on both baseline and test days, and the results were averaged for analysis. This force was measured in grams/grams initial body weight.

Statistical analysis. Statistical analysis of the data was performed by means of the Student's t-test.

\section{Results and Discussion}

As can be seen in Fig. 1, the growth of the tumour has two clear phases. In the first one, following a certain lag, the tumour grows exponentially until day 7 after tumour inoculation, when it enters the second phase, which is clearly stationary, since the number of doubling cells equals that of the dying ones. This fast tumour growth induces weight loss from day 4 onwards with a maximum of about $22 \%$ (Fig. 1). Interestingly, as can be seen in Fig. 1, no anorexia exists until about day 4 when the animals progressively stop eating. At day 10 after tumour inoculation, the reduction in food intake accounts for $87 \%$. Previous studies carried out in our laboratory have shown that weight loss in this animal model is associated with both adipose and skeletal muscle wasting $(6,7)$.

The muscle loss is due to several factors that include increased proteolysis (5), increased apoptosis (15), increased amino acid oxidation $(19,20)$ and decreased muscle regeneration $(21,22)$.

Bearing all this in mind, the objective of the present investigation was to see to what extent the loss of weight, particularly muscle, is reflected into the physical performance of the animals. As can be seen in Fig. 2, tumour growth is associated with a decreased total physical activity as measured by the total number of movements undertaken by the animals for a period of $24 \mathrm{~h}$. The decrease is already significant at day 4 . Interestingly, when total activity is separated into the two light phases, the differences induced by the tumour burden are more marked during the dark phase (night). It is well known that rodents are normally more active during this phase (23). The decrease in physical activity affects both locomotor (movements with displacement) and stereotyped (movements without displacement: eating and cleaning) movements. Again, the decreased activity is more marked for both types of movements during the dark

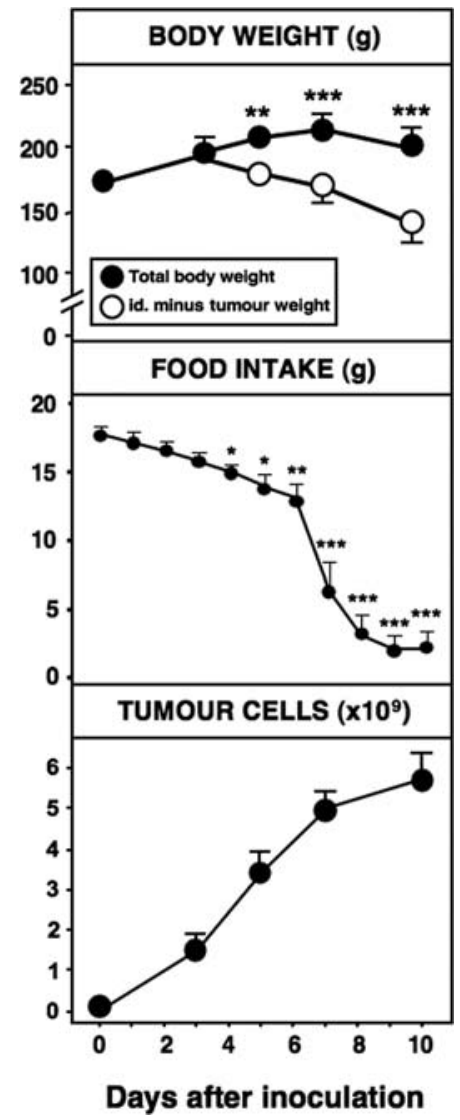

Figure 1. Body weight, food intake and tumour content in rats bearing the Yoshida AH-130 ascites hepatoma. Results are mean \pm SEM for 8 animals. Food intake is expressed in gram ( $\mathrm{g}$ ) and refers to the ingestion during the period of the experiment prior to sacrifice which took place 10 days after tumour inoculation. Body weight is expressed in g. Tumour cell content is expressed in millions of cells. Values that are significantly different by the Student's t-test from the non-tumour-bearing animals group are indicated by ${ }^{*} \mathrm{p}<0.05,{ }^{* *} \mathrm{p}<0.01,{ }^{* * *} \mathrm{p}<0.001$.

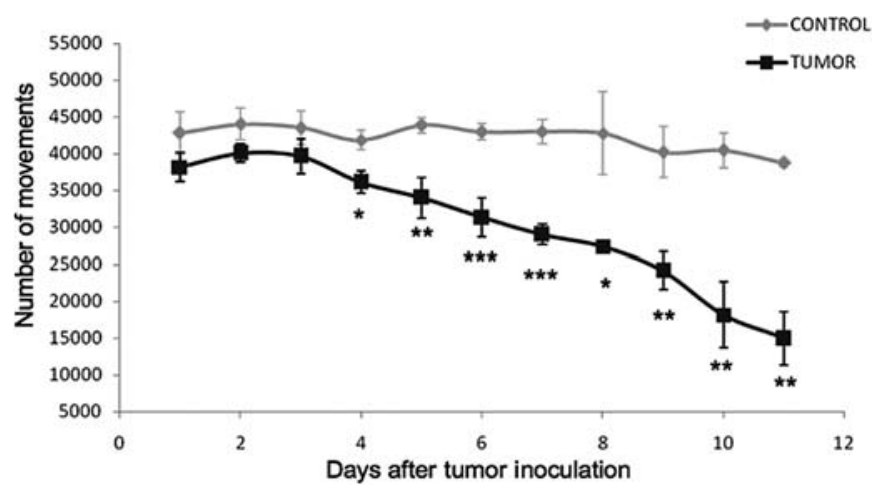

Figure 2.Twenty-four hours total physical activity in rats bearing the Yoshida AH-130 ascites hepatoma. For more details, see the experimental section. Results are mean \pm SEM for 8 animals. Number of movements includes the total number of movements (locomotor and stereotyped movements) performed by the animals. Values that are significantly different by the Student's t-test from the non-tumour-bearing animals group are indicated by ${ }^{*} \mathrm{p}<0.05,{ }^{* *} \mathrm{p}<0.01,{ }^{* * *} \mathrm{p}<0.001$.

phase (Fig. 3). In Fig. 4, the distance covered by the tumourbearing rats is depicted. The distance decreases as tumour burden increases and again it seems to be affected more 
A
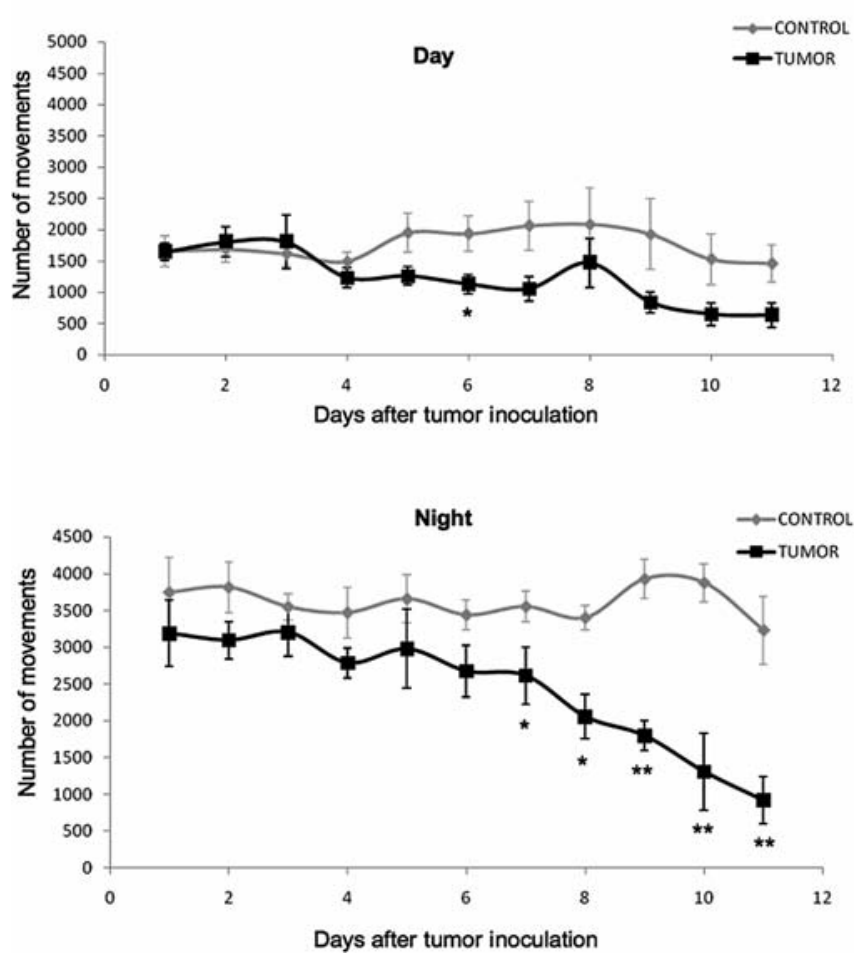

B
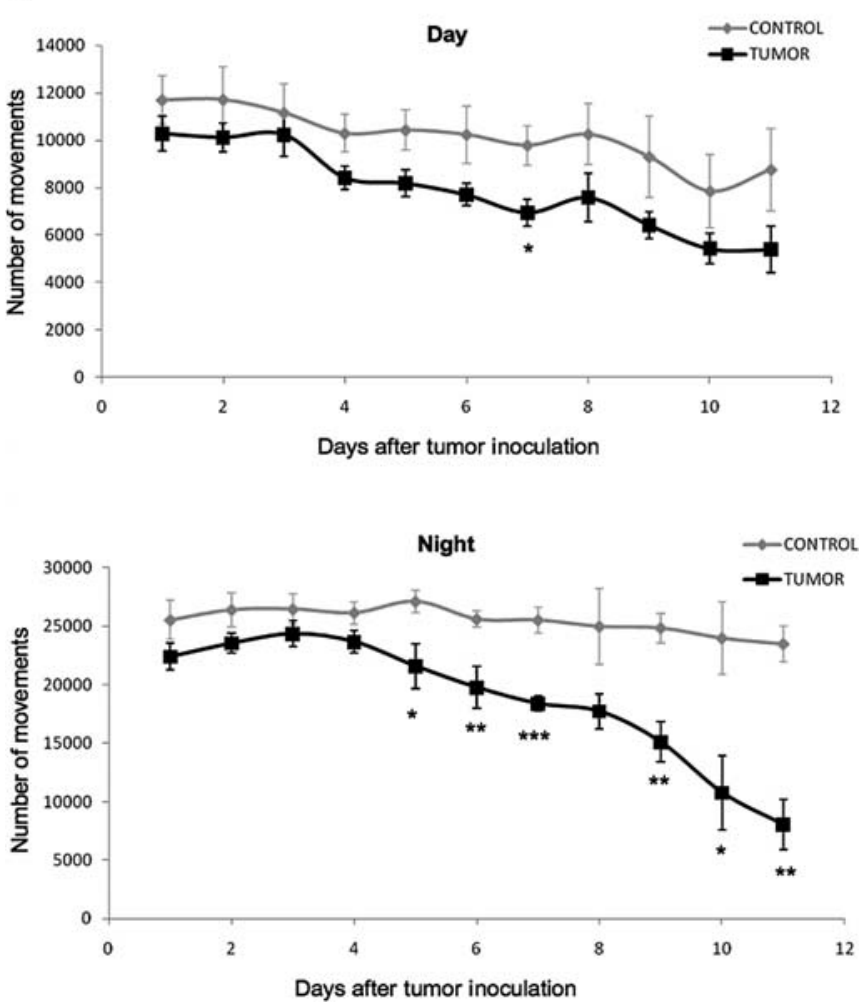

Figure 3. Light and dark phase physical activity in rats bearing the Yoshida AH-130 ascites hepatoma. (A) Stereotyped movements include movements without displacement, i.e. eating and cleaning movements. For more details, see the experimental section. Results are mean \pm SEM for 8 animals. Values that are significantly different by the Student's t-test from the non-tumourbearing animals group are indicated by ${ }^{*} \mathrm{p}<0.05,{ }^{* *} \mathrm{p}<0.01,{ }^{* * * *} \mathrm{p}<0.001$. (B) Locomotor movements include movements with displacement. For more details, see the experimental section. Results are mean \pm SEM for 8 animals. Values that are significantly different by the Student's t-test from the non-tumour-bearing animals group are indicated by ${ }^{*} \mathrm{p}<0.05,{ }^{* *} \mathrm{p}<0.01$, **** $\mathrm{p}<0.001$.

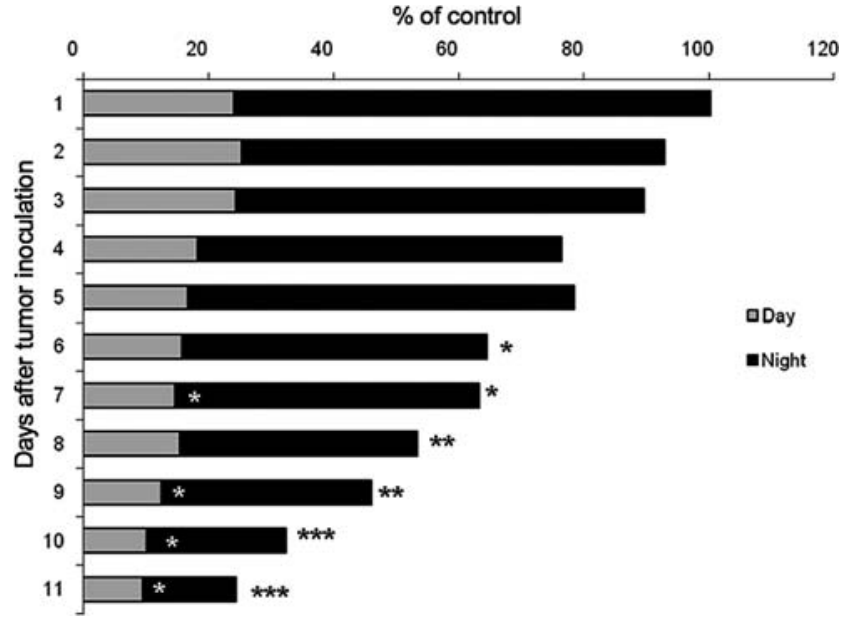

Figure 4. Light and dark phase distance travelled in rats bearing the Yoshida AH-130 ascites hepatoma. For more details, see the experimental section. Results are mean \pm SEM for 8 animals. Results are expressed as percentage of control (non-tumour-bearing animals). Values that are significantly different by the Student's t-test from the non-tumour-bearing animals group are indicated by ${ }^{*} \mathrm{p}<0.05,{ }^{* *} \mathrm{p}<0.01,{ }^{* * *} \mathrm{p}<0.001$.

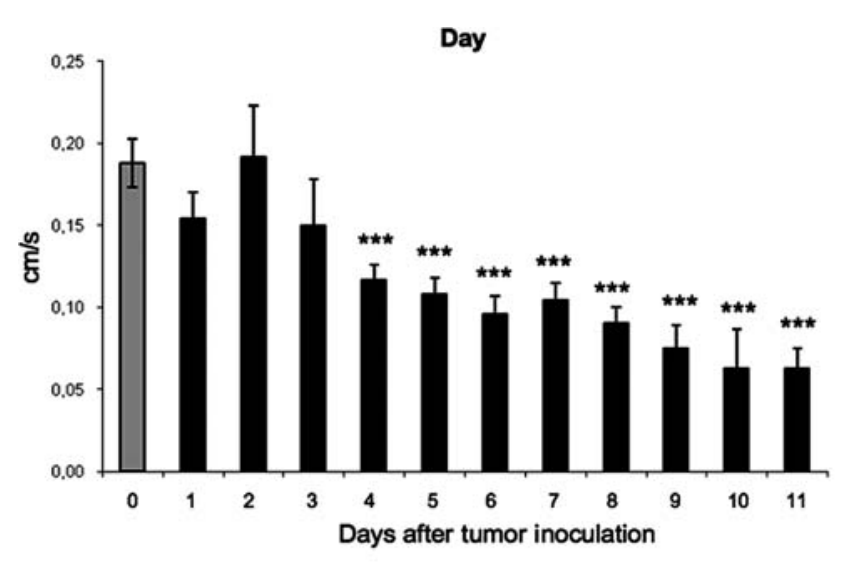

Night

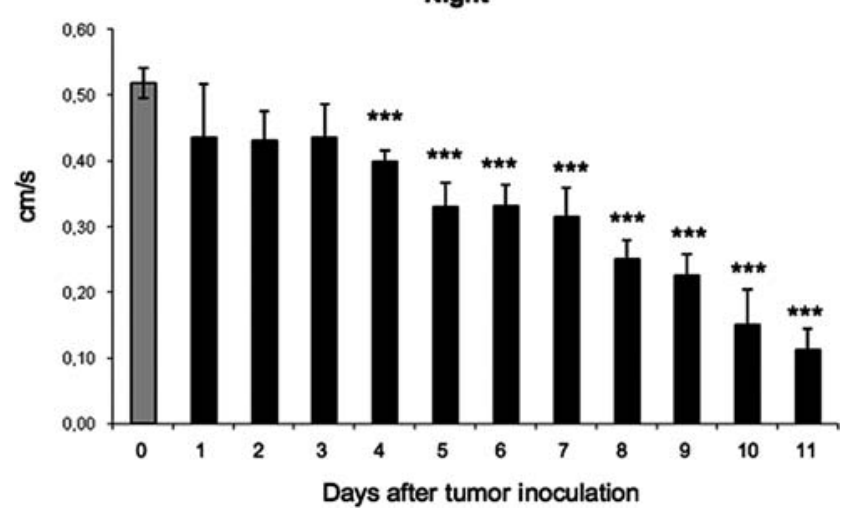

Figure 5. Light and dark phase average velocity in rats bearing the Yoshida AH-130 ascites hepatoma. For more details, see the experimental section. Results are mean \pm SEM for 8 animals. Results are expressed as $\mathrm{cm} / \mathrm{s}$. Values that are significantly different by the Student's t-test from time 0 are indicated by ${ }^{*} \mathrm{p}<0.05,{ }^{* *} \mathrm{p}<0.01,{ }^{* * *} \mathrm{p}<0.001$.

severely during the dark phase. Interestingly, in addition to the distance travelled by the animals, the velocity of the displacement is also decreased as a result of tumour inoculation (Fig. 5). Again, the presence of the tumour seems 

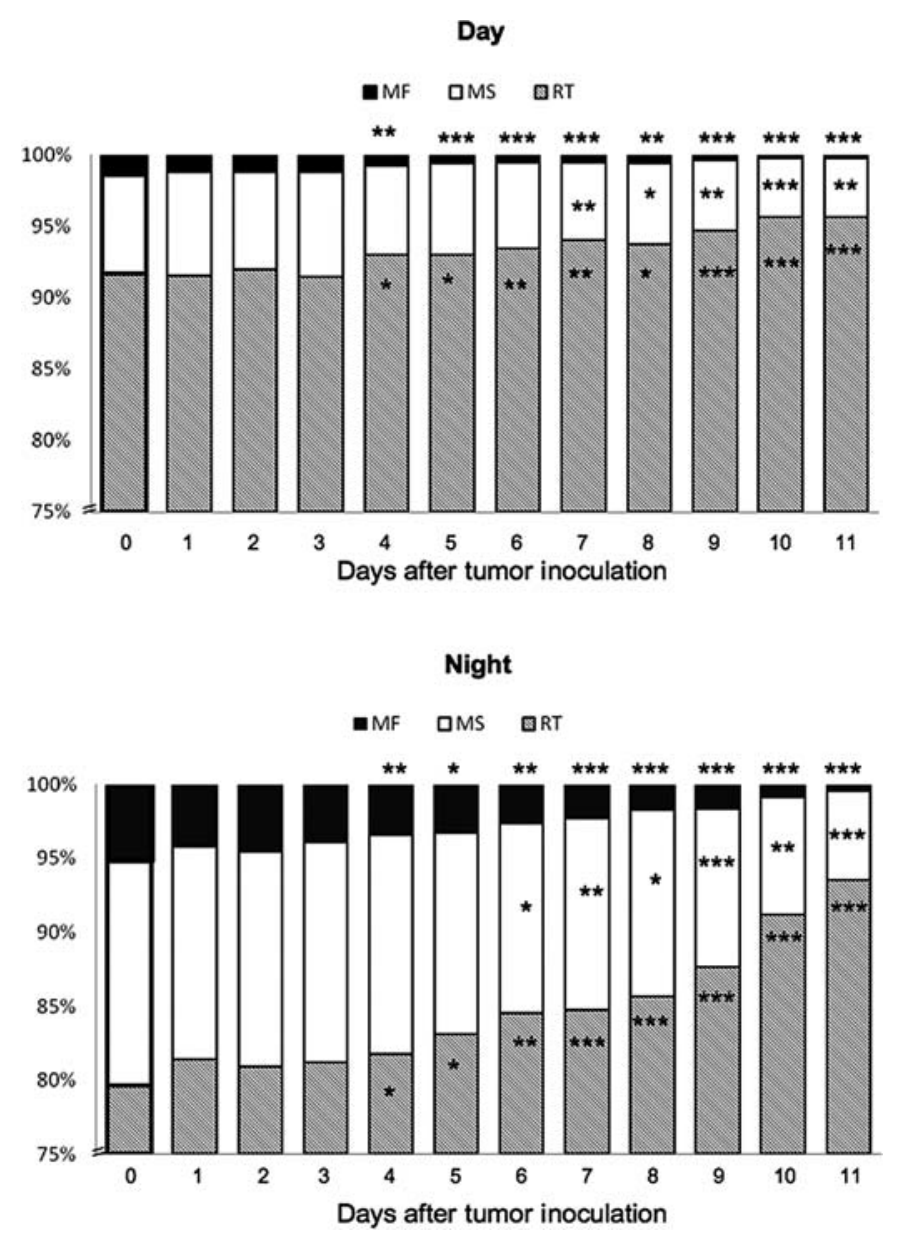

Figure 6. Time involved in resting, slow and fast movements during light and dark phase in rats bearing the Yoshida AH-130 ascites hepatoma. For more details, see the experimental section. Results are mean \pm SEM for 8 animals. Results are expressed as percentage of total time. RT, time involving resting (sleeping, cleaning and eating time), $0-2 \mathrm{~cm} / \mathrm{s} ; \mathrm{MS}$, time involving slow movements, $2-5 \mathrm{~cm} / \mathrm{s} ; \mathrm{MF}$, time involving fast movements, $>5 \mathrm{~cm} / \mathrm{s}$. Values that are significantly different by the Student's t-test from time 0 are indicated by ${ }^{*} \mathrm{p}<0.05,{ }^{* *} \mathrm{p}<0.01,{ }^{* * *} \mathrm{p}<0.001$.

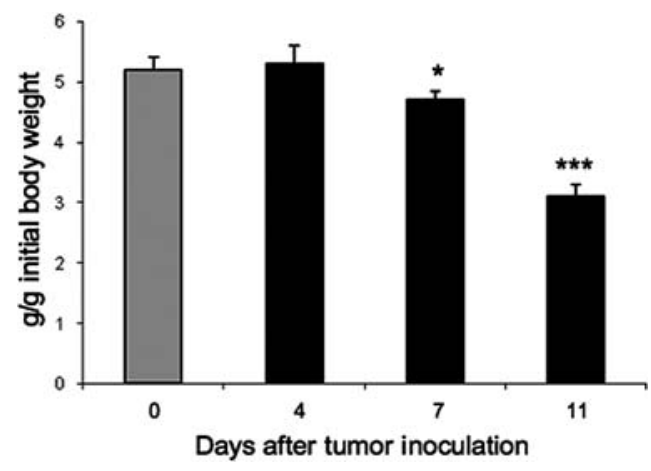

Figure 7. Grip force in cachectic tumour-bearing rats. For more details, see the experimental section. Results are mean \pm SEM for 8 animals. Results are expressed as $\mathrm{g} / \mathrm{g}$ initial body weight. Values that are significantly different by the Student's t-test from the non-tumour-bearing animals group are indicated by ${ }^{*} \mathrm{p}<0.05,{ }^{* *} \mathrm{p}<0.01,{ }^{* * *} \mathrm{p}<0.001$.

to influence the velocity of the animals to a higher extent during the dark phase. Finally, as expected, the time involved in physical activity is also influenced by tumour-burden. Indeed, as can be seen in Fig. 6, resting time was increased with tumour burden in the light and dark phases. Conversely, slow and fast movement times were significantly decreased as tumour presence increased, the difference being more marked in the dark phase. Similar results have been described in humans under cancer cachexia $(24,25)$. In experimental animals, similar results have also been found using the C26 adenocarcinoma model (26).

Interestingly, as can be seen in Fig. 7, tumour inoculation also resulted in decreased muscle force as measured by the griping power of the animals.

From the results presented here, it can be concluded that muscle waste associated with experimental cancer leads to substantial decrease in physical performance.

\section{Acknowledgements}

This study was supported by grants from the Ministerio de Ciencia y Tecnología (SAF-02284-2008) and from the Ministerio de Sanidad y Consumo (PI060907).

\section{References}

1. Tessitore L, Bonelli G, Cecchini G, Amenta JS and Baccino FM: Regulation of protein turnover versus growth state: ascites hepatoma as a model for studies both in the animal and in vitro. Arch Biochem Biophys 255: 372-384, 1987.

2. Marzabal M, Garcia-Martinez C, Comas J, Lopez-Soriano FJ and Argiles JM: A flow cytometric study of the rat Yoshida AH-130 ascites hepatoma. Cancer Lett 72: 169-173, 1993.

3. Costelli P, Muscaritoli M, Bonetto A, et al: Muscle myostatin signalling is enhanced in experimental cancer cachexia. Eur J Clin Invest 38: 531-538, 2008.

4. Fuster G, Busquets S, Ametller E, et al: Are peroxisome proliferator-activated receptors involved in skeletal muscle wasting during experimental cancer cachexia? Role of beta2adrenergic agonists. Cancer Res 67: 6512-6519, 2007.

5. Llovera M, Garcia-Martinez C, Agell N, Lopez-Soriano FJ and Argiles JM: Muscle wasting associated with cancer cachexia is linked to an important activation of the ATP-dependent ubiquitinmediated proteolysis. Int J Cancer 61: 138-141, 1995.

6. Costelli P, Garcia-Martinez C, Llovera M, et al: Muscle protein waste in tumor-bearing rats is effectively antagonized by a beta 2 -adrenergic agonist (clenbuterol). Role of the ATP-ubiquitindependent proteolytic pathway. J Clin Invest 95: 2367-2372, 1995.

7. Busquets S, Figueras MT, Fuster G, et al: Anticachectic effects of formoterol: a drug for potential treatment of muscle wasting. Cancer Res 64: 6725-6731, 2004.

8. Argiles JM, Alvarez B and Lopez-Soriano FJ: The metabolic basis of cancer cachexia. Med Res Rev 17: 477-498, 1997.

9. Llovera M, Garcia-Martinez C, Lopez-Soriano J, et al: Role of TNF receptor 1 in protein turnover during cancer cachexia using gene knockout mice. Mol Cell Endocrinol 142: 183-189, 1998.

10. Rivera S, Azcon-Bieto J, Lopez-Soriano FJ, Miralpeix M and Argiles JM: Amino acid metabolism in tumour-bearing mice. Biochem J 249: 443-449, 1988.

11. Harvey KB, Bothe A Jr and Blackburn GL: Nutritional assessment and patient outcome during oncological therapy. Cancer 43: 2065-2069, 1979.

12. Nixon DW, Heymsfield SB, Cohen AE, et al: Protein-calorie undernutrition in hospitalized cancer patients. Am J Med 68: 683-690, 1980.

13. DeWys W: Management of cancer cachexia. Semin Oncol 12: 452-460, 1985.

14. Argiles JM, Garcia-Martinez C, Llovera M and Lopez-Soriano FJ: The role of cytokines in muscle wasting: its relation with cancer cachexia. Med Res Rev 12: 637-652, 1992.

15. Van Royen M, Carbo N, Busquets S, et al: DNA fragmentation occurs in skeletal muscle during tumor growth: a link with cancer cachexia? Biochem Biophys Res Commun 270: 533-537, 2000 . 
16. Tessitore L, Costelli P, Bonetti G and Baccino FM: Cancer cachexia, malnutrition, and tissue protein turnover in experimental animals. Arch Biochem Biophys 306: 52-58, 1993.

17. Sinis N, Guntinas-Lichius O, Irintchev A, et al: Manual stimulation of forearm muscles does not improve recovery of motor function after injury to a mixed peripheral nerve. Exp Brain Res 185: 469-483, 2008.

18. Zangarelli A, Chanseaume E, Morio B, et al: Synergistic effects of caloric restriction with maintained protein intake on skeletal muscle performance in 21-month-old rats: a mitochondriamediated pathway. FASEB J 20: 2439-2450, 2006.

19. Garcia-Martinez C, Lopez-Soriano FJ and Argiles JM: Alanine metabolism in rats bearing the Yoshida AH-130 ascites hepatoma. Cancer Lett 87: 123-130, 1994.

20. Costelli P, Llovera M, Garcia-Martinez C, Carbo N, LopezSoriano FJ and Argiles JM: Enhanced leucine oxidation in rats bearing an ascites hepatoma (Yoshida $\mathrm{AH}-130$ ) and its reversal by clenbuterol. Cancer Lett 91: 73-78, 1995.
21. Mehl KA, Davis JM, Berger FG and Carson JA: Myofiber degeneration/regeneration is induced in the cachectic apcmin/+ mouse. J Appl Physiol 99: 2379-2387, 2005.

22. Coletti D, Moresi V, Adamo S, Molinaro M and Sassoon D: Tumor necrosis factor-alpha gene transfer induces cachexia and inhibits muscle regeneration. Genesis 43: 120-128, 2005.

23. Lane-Petter W: The physical environment of rats and mice. Academic Press, London, 1963.

24. Fouladiun M, Korner U, Gunnebo L, Sixt-Ammilon P, Bosaeus I and Lundholm K: Daily physical-rest activities in relation to nutritional state, metabolism, and quality of life in cancer patients with progressive cachexia. Clin Cancer Res 13: 6379-6385, 2007.

25. Kulstad R and Schoeller DA: The energetics of wasting diseases. Curr Opin Clin Nutr Metab Care 10: 488-493, 2007.

26. Van Norren K, Kegler D, Argiles JM, et al: Dietary supplementation with a specific combination of high protein, leucine, and fish oil improves muscle function and daily activity in tumour-bearing cachectic mice. Br J Cancer 100: 713-722, 2009. 